\title{
A structured approach to performance measurement and benchmarking for manufacturing enterprises
}

\author{
J. Browne and P. Jordan \\ CIMRU, National University of Ireland, Galway, Ireland \\ Tel: $+353-91-750414$ \\ Fax: $+353-91-562894$ \\ Email: jimmie.browne@ucg.ie
}

\begin{abstract}
Industry is faced with the challenge of adopting best practice in business processes. To identify best practice it is necessary to measure the performance of business processes in enterprises. The approach presented in this paper is based on the ENAPS (ESPRIT 2088) methodology for performance measurement and benchmarking. The ENAPS project seeks to accomplish this through setting up a performance benchmarking network to span all European countries. This paper describes the three-stage process used in ENAPS; (1) identification of dimensions of performance, (2) definition of a generic business model with business processes and sub-processes and (3) definition of performance indicators for each process and sub-process along each dimension of measurement. A European-wide network has been established to apply the
\end{abstract}


performance benchmarking methodology. The set-up and functioning of the network is outlined in the paper.

\section{Keywords}

Performance measurement, benchmarking.

\subsection{INTRODUCTION}

Often performance measurement approaches are applied on an ad-hoc basis. The ENAPS methodology sets out a structured approach to performance measurement of a manufacturing enterprise with the aim of subsequent benchmarking of the enterprise against best practice. There are three main dimensions to this structured approach. Firstly, a set of global performance measurements is developed. These are cost, time, quality, flexibility and environment. Secondly, a generic set of business processes for a manufacturing enterprise is developed. These include customer order fulfilment, product development, obtaining customer commitment and after sales service. Finally a manufacturing typology is used to cover each type of manufacturing. This typology covers make to stock, assemble to order, make to order and engineer to order manufacturers.

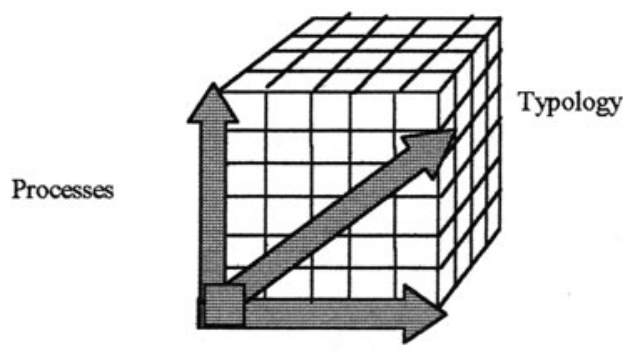

Global performance indicators (Time, cost, quality etc.)

Figure 1 The ENAPS performance measurement cube.

These three dimensions of the methodology are represented as a cube in Figure 1. Each element of the cube is then assigned a set of performance indicators. Any single performance indicator will apply to a particular aspect of a business process within a particular type of manufacturing. For example, the performance indicator customer order fulfilment time may be a performance indicator relating to "time" of the customer order fulfilment process within make to stock manufacturing. 


\subsection{IDENTIFYING GLOBAL PERFORMANCE INDICATORS}

Within an enterprise, there are a variety of aspects of performance that need to be monitored. In the past enterprises concentrated on cost as the main dimension of measurement. Although cost is still of great importance it is becoming increasingly evident that other dimensions of performance are crucial to the success of an enterprise (Bredrup, 1995).

Recently, many enterprises are concerned with the dimension of time. Such issues as delivery times, product development lead times and customercomplaint response times are becoming crucial. Customers now expect short lead times and hence time is a very important dimension of measurement.

Quality has become established as a crucial aspect of competitive advantage for enterprises also. To ensure increased customer satisfaction, the dimension of quality should be measured where the scope of "quality" should not be simply restricted to product quality but also to quality in a more general sense. With the increased desire for variety and the uncertainty that this causes, enterprises are becoming increasingly aware of the need for flexibility within their business processes. The processes must be capable of handling variety and uncertainty and thus it is crucial to measure performance in terms of flexibility. Finally, governments and customers are becoming more aware of the need to protect the environment. It is now becoming increasingly important to measure performance related to environmental-friendliness.

In summary the five important dimensions of measurement are:

- Cost.

- Time.

- Quality.

- Flexibility.

- Environment.

These global performance indicators were used by the ENAPS project to determine performance indicators to use in measurement and benchmarking.

\subsection{A GENERIC BUSINESS MODEL}

Once the dimensions of measurement have been derived it must be decided what processes should be measured. The Extended ENAPS Business Model is shown in Figure 2. This model is based on the concept of the extended 
enterprise (Browne et al., 1994). This model identifies the various functions within an extended enterprise including links to the customer, supplier, recycler, and service provider.

There are three types of flow identified in the model: The flow of material, the flow of technical information and the flow of business information. Material, in the form of raw material, components, manufactured product, and recycled product flows in the chain from supplier through the customer to the recycler and service provider. Technical information flows from the customer back to marketing and design within the enterprise in the form of requirements. There is also an exchange of technical information between the enterprise design group and manufacturing and suppliers in the form of design specifications for the purpose of co-engineering. The main flow of business information comes from the customer in the form of a customer order, which enters the enterprise through the production planning and control function, which then passes instructions to suppliers, manufacturing and assembly.

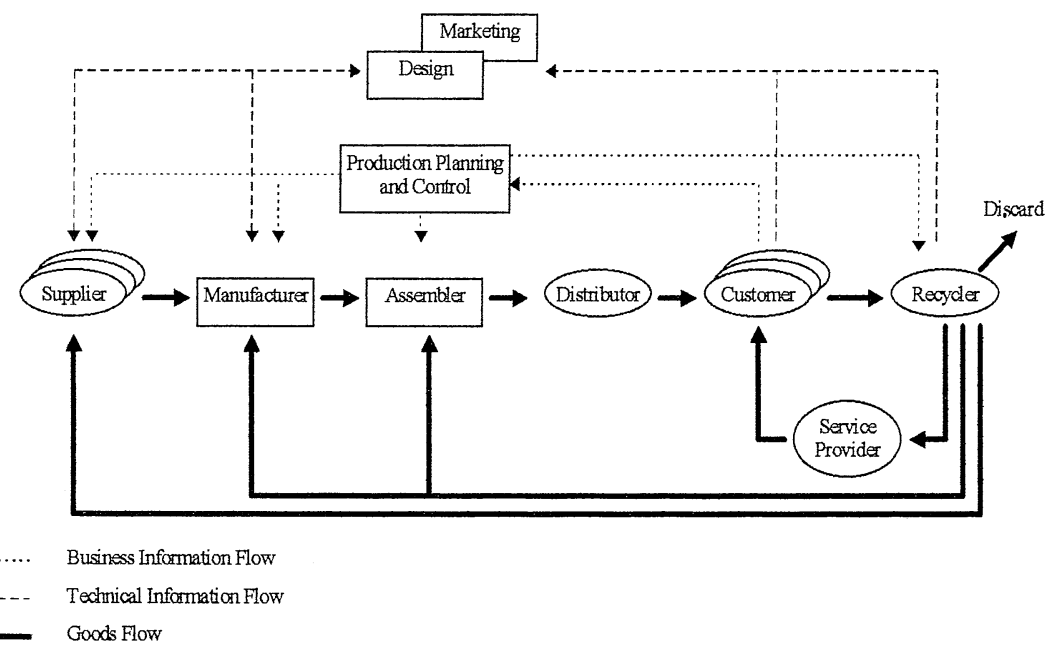

Figure 2. The Extended ENAPS Business Model

From the extended business model, a generic set of business processes within an extended enterprise can be derived. These are identified as:

1. PRODUCT DEVELOPMENT: All activities involved in researching, designing, engineering (including co-engineering) and releasing products to manufacturing. 
2. OBTAINING CUSTOMER COMMITMENT: All activities involved from market analysis to sales.

3. ORDER FULFILLMENT: All activities from receipt of an order until the customer has received and paid for the product.

4. CUSTOMER SERVICE: All activities involved in providing after-sales service including product take back.

The breakdown of these processes into a generic set of sub-processes is shown in Figure 3.

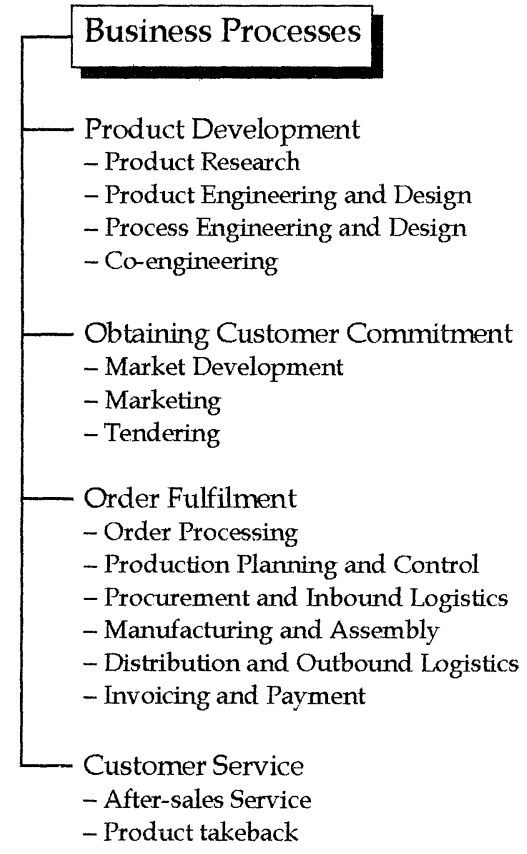

\section{Secondary Processes}

Support

- Financial Management

- Human Resource Management

- Information Management

- Maintenance

- Internal Control of Health, Environment and Safety

Evolution

- Continuous Business Process Improvement

- Human Resource Development

- Supplier Base Development

- Development of External Relations

-Strategic Planning

Figure 3 ENAPS generic enterprise process model.

This ENAPS approach is based around the measurement of the performance of core business processes in a manufacturing enterprise. Each business process is broken into sub-processes. Each process and sub-process has a range of performance indicators associated with it along the dimensions of time, cost, quality, flexibility and environment. 


\subsection{MANUFACTURING TYPOLOGIES}

For different types of manufacturing enterprises the requirements for performance indicators will vary. This introduces a third dimension for performance measurement - that of manufacturing typology. The manufacturing typology used in ENAPS is that of the customer order decoupling point (Higgins et. al. 1996). This divides manufacturing enterprises into four categories based on how closely the manufacturing process is related to customer orders. The four categories are make to stock, assemble to order, make to order and engineer to order. Make to stock produces product and stores this in a warehouse. When customer orders are received they are fulfilled directly from stock. Assemble to order manufacturers produce a stock of intermediate components that can be assembled to a customer's specification when an order is received. Make to order manufacturers await a customer order before manufacturing any part of the product. Finally, engineer to order manufacturers begin the customer order fulfilment process by designing a new product specifically for the customer.

In total then there are performance indicators for each process and sub-process for the five dimensions of time, cost, quality, flexibility and environment and for four different manufacturing types. This is represented by the ENAPS performance measurement cube shown in figure 1.

Each element of the cube contains at least one performance indicator. This provides a basic structured set of performance indicators for a manufacturing enterprise.

\subsection{BENCHMARKING}

The ENAPS approach to benchmarking is based on performance benchmarking. Unlike process benchmarking and strategic benchmarking, performance benchmarking is a comparison of exact performance measures. Usually, the purpose is to determine ones status compared to other companies, identify areas or processes in need of improvement, and setting realistic targets based on performance levels achieved by others. The methodology for benchmarking is based on the benchmarking wheel.

The main content of each of the five phases in a typical benchmarking study is:

1. Plan: planning the benchmarking study and laying the groundwork for the coming phases, including selecting the process to be benchmarked and 
thoroughly understanding how that process is performed within one's own organization.

2. Find: identifying benchmarking partners and obtaining acceptance for their participation in the study.

3. Collect: performing the same thorough documentation of the benchmarking partners' process as was done for ones own in the planning phase.

4. Analyze: finding gaps between the performance of ones own process and that of the benchmarking partners, as well as determining what differences in practice create the performance gap.

5. Improve: implementing improvements based on the findings from the observation and analysis of the benchmarking partners.

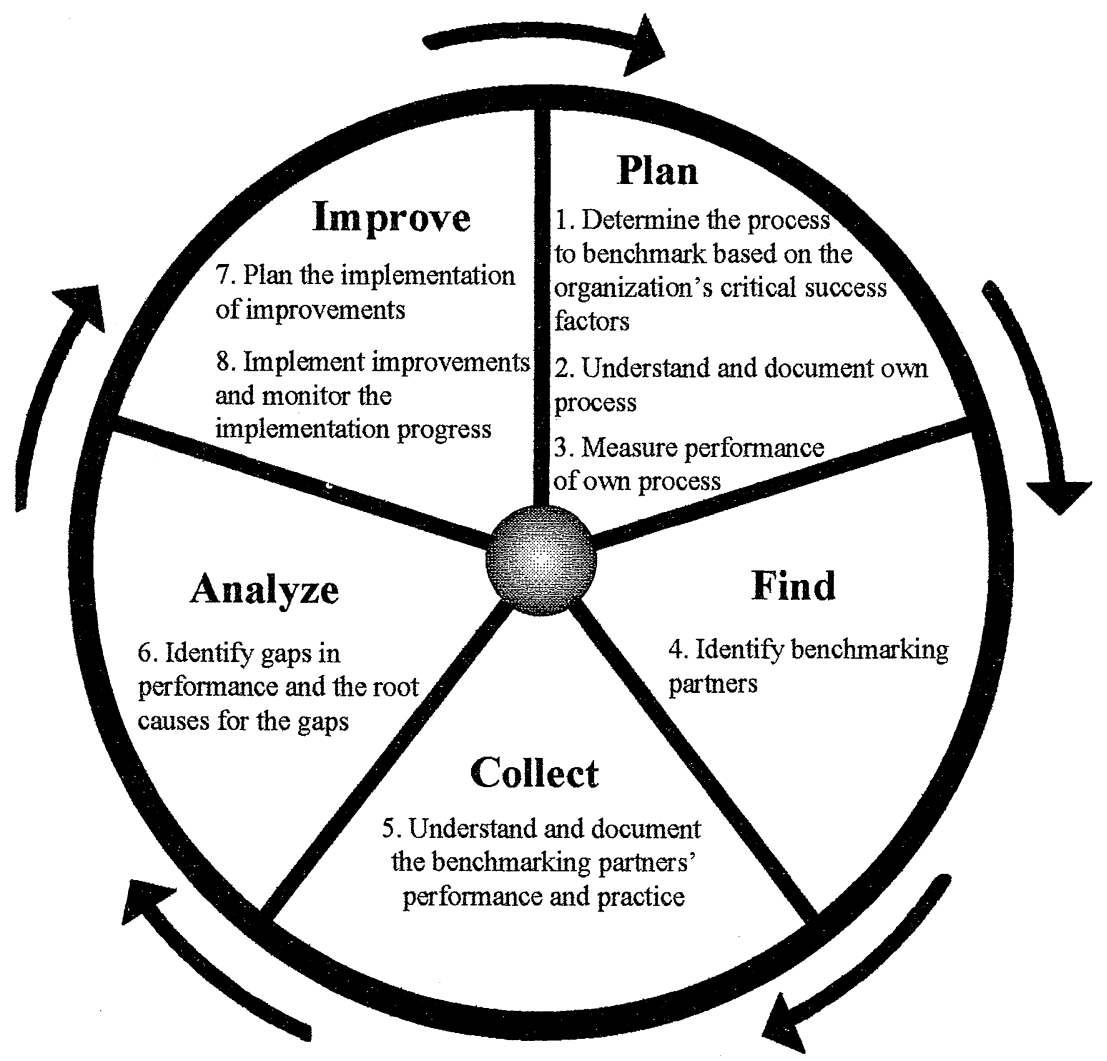

Figure 5 The Benchmarking Wheel (Andersen, B. 1995) 
Each of these five phases poses different challenges for the benchmarking organization, and all of them are vital elements in a complete benchmarking study that eventually will generate the sought improvements.

\subsection{THE ENAPS NETWORK}

ENAPS is a network of agents and academic partners spread throughout Europe. Each agent works directly with manufacturing enterprises by implementing the ENAPS methodology to collect performance measurement data. An electronic questionnaire assists the agents with the data collection process. This data is then stored in a central database, currently administered by one of the academic partners at Bremen in Germany. The data may be anonymous or public depending on the security requirement of the individual enterprises.

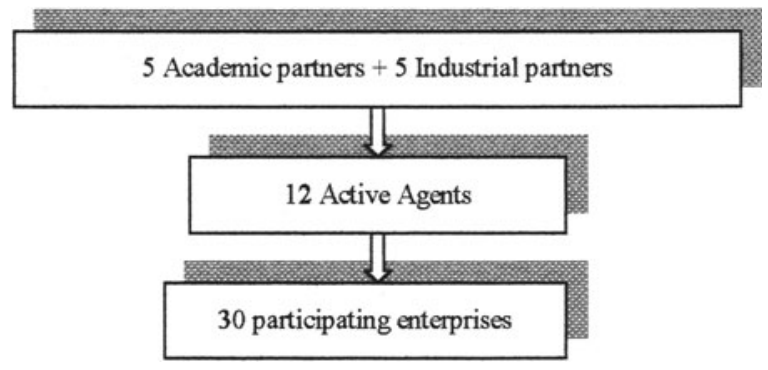

Figure 6

The ENAPS network structure

Once data has been entered by an agent on behalf of an enterprise, it is then possible to carry out queries which will benchmark the enterprises performance against the other enterprises in the database. As the database is still very young there are now only 50 enterprise data sets. This means that only limited benchmarking can be performed. As the number of enterprises in the database increases, so does the benchmarking service the ENAPS network provides.

The structure of the ENAPS network is summarized in Figure 6. There are 5 academic partners and 5 Industrial partners who administrate the project and coordinate the agents. Each agent is associated with a partner. Each agent in turn deals with one or more manufacturing enterprises. One of the aims of ENAPS is to improve the relationship between the agent and the enterprise so that, using the benchmarking results, the agent can assist in implementing improvement plans within the enterprise. The agents will supervise these 
improvement plans and the ENAPS database can be used periodically to monitor improvements against best practice.

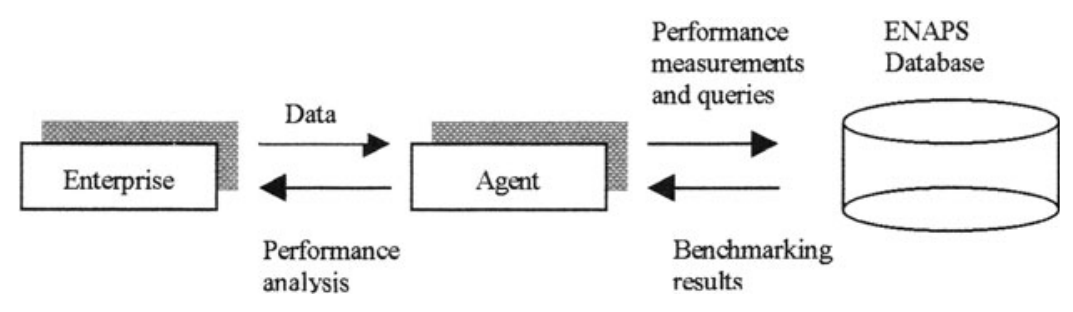

Figure 7

Exchange of information in the ENAPS network

Figure 7 summarizes the exchange of information within the network. Data is collected by the agents and stored in the database as generic ENAPS performance measurements. The agent can perform queries on behalf of the enterprise to obtain benchmarking results. These results can then be used to analyze the performance of the enterprise's business processes.

\subsection{CONCLUSIONS}

The ENAPS approach to improvement is based on performance measurement and benchmarking. Performance measurement facilitates an enterprise in monitoring key indicators so as to detect trends and highlight improvements or deterioration in enterprise processes. Benchmarking shows an enterprise how well they are doing with respect to other enterprises with similar processes. The importance of the ENAPS approach is that it provides a structure with which to build a consistent and complete set of performance indicators for successful benchmarking manufacturing enterprises. The ENAPS approach is especially suited to SMEs. Many larger companies can benchmark within their own departments or pay large sums of money to an international consultancy firm to help them benchmark. These options are rarely available to SMEs. ENAPS provides a cheap and customised service to these smaller enterprises.

\section{REFERENCES}

Andersen, B. and Pettersen, P. (1996) The Benchmarking Handbook: Step-byStep Instructions. Chapman \& Hall, London, England.

Andersen, B and Jordan, P. (1998) Setting Up a Performance Benchmarking Network, International Journal of Production Planning \& Control, v. 9, no. 1, p. 13-19. 
Andersen, B. (1995) The Results of Benchmarking and a Benchmarking Process Model. Ph.D. Dissertation, The Norwegian Institute of Technology, Trondheim, Norway.

Bredrup, H. (1995) Performance Measurement in a Changing Competitive Industrial Environment: Breaking the Financial Paradigm, Ph.D. Dissertation, Norwegian Institute of Technology, Trondheim, Norway.

Browne, J., Sackett, P.J., and Wortmann J.C. (1994) Industry Requirements and Associated Research Issues in the Extended Enterprise, Proceedings of the IMSE '94 European workshop on Integrated manufacturing systems engineering, Grenoble, France, December 12-14.

Browne, J., Sackett, P.J., and Wortmann J.C. (1994) The Extended Enterprise A Context For Benchmarking, IFIP working group 5.7 workshop on Benchmarking - theory and practice, Trondheim, Norway, June 16-18.

Higgins, P., Le Roy, P., Tierney, L. (1996), Manufacturing Planning and Control: Beyond MRP II. Chapman and Hall. 